\title{
PROCESSO ESTRUTURAL: DA IMPORTÂNCIA DA ATUAÇÃO DO JULGADOR
}

Lillian Zucolote de Oliveira ${ }^{1}$

Luiz Alberto Pereira Ribeiro ${ }^{2}$

\section{RESUMO}

O presente trabalho tem como escopo indicar parâmetros de atuação a serem seguidos pelos magistrados durante a condução de processos estruturais. Para tanto, partiu-se dos esclarecimentos conceituais sobre processos estruturais, da análise das críticas direcionadas ao referido tema e da verificação da postura que deve ser adotada pelo magistrado. Assim, conclui-se que o julgador detém função basilar na condução estrutural do processo, mas que o sucesso do processo somente pode ser alcançado a partir da cooperação de todos os envolvidos. Para isso, utilizou-se o método dedutivo a partir da revisão bibliográfica e documental de doutrinadores pátrios e estrangeiros.

Palavras chave: Condução Processual; Judicialização da Política; Julgador; Poder Judiciário; Problema Estrutural.

\section{STRUCTURAL LITIGACION: THE IMPORTANCE OF THE JUDGE'S PERFORMANCE}

\begin{abstract}
The present work aims to indicate the parameters of action to be followed by the magistrates during the conduction of the structural litigation. It started from the conceptual clarifications about structural litigation, the analysis of the criticisms directed to the referred theme and the verification of the posture that should be adopted by the magistrate. It is concluded that the judge has a fundamental role in the structural conduction of the process, but that the success of the process can only be achieved through the cooperation of all those involved. The deductive method was used from the bibliographical and documental review.
\end{abstract}

Palavras chave: Procedural Conduct; udicialization of the Policy; Judge; Judicial Power; Structural Problem.

\section{INTRODUÇÃO}

É inegável que o Poder Judiciário tem sido cada vez mais invocado para lidar com problemas estruturais, os quais podem estar ligados ao funcionamento inadequado de uma instituição, a violação de direitos fundamentais, a ineficácia ou ausência de política públicas ou a presença de litígios policêntricos. A complexidade de tais litígios coloca em evidência a

\footnotetext{
${ }^{1}$ Mestranda em Direito Negocial pela Universidade Estadual de Londrina (UEL). Especialista em Direito Penal e Processo Penal Econômico pela PUCPR. Especialista em Direito Extrajudicial pela Faculdade Legale. Graduada em Direito pela Universidade Estadual de Londrina (UEL). Advogada. E-mail: lillian.oliveira1997@gmail.com

${ }^{2}$ Mestre em Direito pela Universidade Estadual de Londrina (UEL). Doutor em Direito pela PUCPR. Professor Adjunto do Curso de Direito da PUCPR e da UEL. Professor do Mestrado em Direito Negocial da UEL. Advogado. E-mail: luizribeiro@uel.br
}

CONPEDI LAW REVIEW | EVENTO VIRTUAL | v. 7 | n. 2 | p. 56 - 75 | JUL - DEZ | 2021 
necessidade de que sejam tratados por meio de processos estruturais a fim de que se torne possível alcançar a solução mais adequada ao caso concreto.

Contudo, o estudo sobre os processos estruturais traz à tona críticas feitas a intervenção do Poder Judiciário em questões relacionadas a políticas públicas, bem como questionamentos acerca da postura adequada que deve ser adotada pelo julgador. Nesse ínterim, o presente trabalho tem como objetivo verificar as principais críticas dirigidas ao referido tema e indicar parâmetros de atuação a serem seguidos pelos magistrados durante a condução de processos estruturais.

A pesquisa terá cunho teórico e será desenvolvida à luz do método dedutivo. Para tanto, será realizada a pesquisa exploratória a partir da revisão bibliográfica e documental de importantes doutrinadores pátrios e estrangeiros que tratam acerca do tema, como: Edilson Vitorelli, Fredie Didier Jr., Hermes Zaneti Jr., Rafael Oliveira, Sérgio Arenhart, Marco Felix Jobim, Owen Fiss e Susan Sturm.

A fim de atingir o objetivo almejado, o presente trabalho está estruturado em quatro partes. A primeira abarcará os esclarecimentos iniciais acerca dos litígios estruturais e do processo estrutural. A segunda parte tratará sobre as principais críticas feitas a atuação dos magistrados em litígios estruturais. A terceira se voltará à análise acerca das diferentes abordagens que podem ser adotadas para o desenvolvimento dos processos estruturais. Por fim, a quarta parte apontará para a postura que deve ser adotada pelo magistrado frente a um litígio estrutural.

\section{1 - ESCLARECIMENTO INICIAIS ACERCA DOS LITÍGIOS ESTRUTURAIS E PROCESSOS ESTRUTURAIS.}

O processo civil tradicional foi concebido sob uma lógica bipolarizada do conflito. Segundo Giuseppe Chiovenda (1969, p. 5), “o processo civil [...] se encaminha por demanda de uma parte (autor) em frente a outra (réu)", cabendo ao magistrado resolver o conflito a partir da seleção de uma das partes como vencedora e a outra como perdedora.

Assim, o direito processual brasileiro foi projetado para lidar com litígios individuais, os quais possuem como características o trato linear dos conflitos, a presença de dois centros de interesses, as discussões limitadas aos direitos individuais dos autores e réus, o caráter retrospectivo das soluções, as sentenças condenatórias limitadas na obrigação de 
fazer/não fazer ou pagar determinada quantia, bem como a atuação passiva, secundária e imparcial do magistrado.

Esse modelo processual se amolda razoavelmente bem às demandas marcadas pela predominância de interesses particulares, baixa complexidade ou repercussão social e mínima intervenção estatal. Contudo há conflitos que, em razão da sua alta complexidade, da presença de vários centros de interesse e da violação estrutural de direitos fundamentais, não se adequam a tradicional configuração do processo judicial, uma vez que para a sua solução não basta a escolha entre apenas duas propostas de resolução e tampouco a imposição de uma ordem de fazer ou não fazer, entregar coisa ou pagar quantia.

Tais conflitos são chamados de litígios estruturais, os quais são fortemente marcados pelo policentrismo frente a presença concomitante de vários centros de interesses juridicamente protegidos. Segundo William Fletcher (1982, p. 645), policentrismo é a “característica de problemas complexos, com inúmeros 'centros' problemáticos subsidiários, cada um dos quais se relacionando com os demais, de modo que a solução de cada um depende da solução de todos os outros".

A fim de ilustrar a característica policêntrica de tais conflitos, William Fletcher e Lon L. Fuller (1978, p. 394-395) utilizam da metáfora da teia de aranha: se apenas um dos fios é puxado, isso repercute na teia como um todo implicando sua total reconfiguração. Transpassando tal ideia para o âmbito processual, verifica-se que a imposição de determinada decisão judicial visando solucionar tais conflitos poderá gerar repercussões por toda a rede de interessados, bem como a sociedade em geral.

Assim, a policentria coloca em evidência a complexidade dos litígios estruturais, bem como aponta para a urgência da implementação de um tratamento adequado aos conflitos de caráter estrutural. Nesse ínterim, antes de adentrar na análise sobre a atuação do Poder Judiciário diante de tais litígios, é necessário esclarecer conceitualmente o que são litígios estruturais e processos estruturais.

Segundo Edilson Vitorelli (2018, p. 338), litígios estruturais são litígios coletivos que surgem "em decorrência do funcionamento de uma estrutura burocrática, pública ou privada, e, em virtude das características contextuais em que ocorre, sua solução exige a reestruturação do funcionamento da estrutura". Desse modo, entende-se que os conflitos de caráter estrutural só serão efetivamente resolvidos a partir da mudança de comportamento de instituições públicas ou privadas. 
Seguindo essa mesma linha de raciocínio, Edilson Vitorelli (2020, p. 60) entende o processo estrutural como "um processo coletivo no qual se pretende, pela atuação jurisdicional, a reorganização de uma estrutura burocrática, pública ou privada, que causa, fomenta ou viabiliza a ocorrência de uma violação pelo modo como funciona, originando um litígio estrutural”.

Soma-se a esse conceito o entendimento trazido por Owen Fiss (2004, p. 27), doutrinador norte-americano, segundo o qual o processo de caráter estrutural seria "aquele no qual um juiz, enfrentando uma burocracia estatal no que tange aos valores de âmbito constitucional, incumbe-se de reestruturar a organização para eliminar a ameaça imposta a tais valores pelos arranjos institucionais existentes".

Por sua vez, Fredie Didier Jr, Hermes Zaneti Jr e Rafael Oliveira (2017, p. 104) conceituam o processo estrutural a partir da existência de um problema estrutural.

O problema estrutural se define pela existência de um estado de desconformidade estruturada - uma situação de ilicitude contínua e permanente ou uma situação de desconformidade, ainda que não propriamente ilícita, no sentido de ser uma situação que não corresponde ao estado de coisas considerado ideal.

Assim, a decisão estrutural é entendida como "aquela que busca implantar uma reforma estrutural (structural reform) em um ente, organização ou instituição, com o objetivo de concretizar um direito fundamental, realizar uma determinada política pública ou resolver litígios complexos" (DIDIER, ZANETI, OLIVEIRA, 2017, p. 109).

A partir dos conceitos colacionados acima, é possível perceber que para Edilson Vitorelli o processo estrutural será sempre um processo coletivo e está voltado para a reestruturação de uma instituição pública ou privada que violou norma legal, enquanto que para Fredie Didier Jr, Hermes Zaneti Jr e Rafael Oliveira o processo estrutural tem o objetivo de reestruturar um estado de desconformidade causado pela prática de atos ilícitos ou não e que pode estar ligado ao funcionamento de uma instituição, a violação de direitos fundamentais, a ineficácia ou inexistência de políticas públicas e/ou a necessidade de resolução de litígios complexos.

O presente estudo não tem o objetivo de destrinchar as conceituações trazidas pela doutrina, mas apenas de apresentar noções básicas sobre o que pode ser entendido como processo estrutural com o objetivo de analisar qual a postura que deve ser adotada pelo julgador na condução de um processo estrutural. Diante disso, é importante esclarecer que para a elaboração da presente pesquisa adota-se o conceito mais abrangente de processo 
estrutural abordado por Fredie Didier Jr, Hermes Zaneti Jr e Rafael Oliveira, mas sem com isso desprezar os ensinamentos de Edilson Vitorelli.

Em relação às características típicas do processo estrutural, Didier, Zaneti e Oliveira (2017, p. 110) as dividem em essenciais e não essenciais. Segundo referidos autores, as características típicas e não essenciais são: a multipolaridade (diversos núcleos de posições e opiniões), a coletividade (situação jurídica coletiva) e a complexidade (processo que discute um problema que admite diversas soluções).

Por sua vez, as características típicas e essenciais do processo estrutural, são: o problema estrutural, a implementação de um estado ideal de coisas, o procedimento bifásico e flexível e a consensualidade (DIDIER, ZANETI, OLIVEIRA, 2017, p. 114).

Para concluir os esclarecimentos iniciais a respeito dos processos estruturais, é importante ressaltar que a existência de um litígio estrutural não necessariamente levará a propositura de um processo estrutural, ou seja, é possível que litígios estruturais sejam tratados em processos individuais, coletivos ou estruturais. Isso se dá porque inexiste uma correlação compulsória entre o tipo de litígio e o tipo de processo.

Contudo, é de toda forma indicado que litígios estruturais sejam tratados em processos estruturais a fim de que seja possível a promoção de uma verdadeira reestruturação da situação de desconformidade a partir da compreensão ampla do conflito, da prolação de decisões judiciais voltadas para o futuro, da abertura ao diálogo entre os interessados e da permanente flexibilização procedimental.

Assim, observa-se que a efetiva resolução de litígios estruturais está condicionada a mudança de postura do julgador. O processo estrutural exige que o magistrado adote uma postura mais ativa e busque construir um ambiente colaborativo e democrático com o objetivo de obter as melhores soluções para o conflito. Isso porque um processo só é bom na medida em que for capaz de resolver o problema apresentado e, para tanto, é essencial que o magistrado esteja disposto a ser um agente de mudança.

No entanto, esse novo papel atribuído ao magistrado pelo processo estrutural é pauta de amplas discussões no meio jurídico, havendo inclusive aqueles que defendem que os litígios estruturais devem ser completamente afastados do crivo do Poder Judiciário em razão da sua suposta intervenção nos espaços de decisão do Poder Legislativo e Executivo. A seguir será abordado acerca das principais críticas feitas a atuação dos magistrados frente aos conflitos de caráter estrutural. 


\section{2 - DA ATUAÇÃO DO PODER JUDICIÁRIO FRENTE AOS LITÍGIOS ESTRUTURAIS.}

O processo estrutural atribui ao magistrado o papel de dar significado aos valores constitucionais e reestruturar um estado de desconformidade. Entretanto, para que os litígios estruturais sejam efetivamente solucionados, é necessário que o processo se adapte. Nesse sentido, as especificidades dos conflitos de caráter estrutural exigem a construção de um processo constitucional democrático, bem como a redefinição de alguns aspectos atinentes à própria função judicial e a postura que deve ser adotada pelo magistrado frente ao conflito.

É inegável que o Poder Judiciário tem sido chamado cada vez mais para intervir em outras esferas de poder visando a efetivação de direitos fundamentais e de políticas públicas. Em geral, tal cenário advém da inércia dos Poderes Legislativo e Executivo e do dever de atuação do Poder Judiciário. Segundo Marco Félix Jobim (2013, p. 104),

“[...] quando o Poder Legislativo não consegue atribuir ao povo novas leis que possam modificar esse ambiente ou quando o Poder Executivo fica inerte em seu dever de administrar, é o Poder Judiciário que deverá intervir, em ambos os casos, por meio de processo individuais ou coletivos".

Nesse contexto, observa-se a presença do fenômeno chamado judicialização da política. De acordo com Luís Roberto Barroso (2012, p. 24) "judicialização significa que algumas questões de larga repercussão política ou social estão sendo decididas por órgãos do Poder Judiciário, e não pelas instâncias políticas tradicionais: o Congresso Nacional e o Poder Executivo".

Referido fenômeno decorre da constitucionalização de direitos e liberdades fundamentais somado ao fortalecimento do controle judicial de constitucionalidade e ao incremento do acesso à justiça. Assim, observa-se nos últimos anos uma modificação na forma de atuação do Poder Judiciário que passou a decidir questões complexas de grande repercussão política e social, o que, consequentemente, resultou na "transferência de poder para juízes e tribunais, com alterações significativas na linguagem, na argumentação e no modo de participação da sociedade" (BARROSO, 2012, p. 24).

Esse novo papel atribuído aos juízes e tribunais com a possibilidade de intervir na atividade legislativa e administrativa não está isento de críticas, em especial aquelas relacionadas à temática do ativismo judicial e da suposta violação ao princípio da separação 
dos poderes. O termo ativismo judicial possui inúmeros significados podendo ser interpretado de forma pejorativa, apreciativa ou neutra. Contudo, seja qual for a visão adota, a ideia do ativismo judicial costuma estar associada a "maior interferência do Judiciário no espaço de atuação dos outros dois Poderes" (BARROSO, 2012, p. 25).

De fato, está correto o entendimento de que os processos estruturais imputam ao juiz uma postura que é contrária a ideia de poderes completamente limitados. Entretanto, isso não quer dizer que os processos estruturais são uma manifestação do ativismo judicial no sentido de representar uma atuação indevida ou ilegítima do Poder Judiciário.

Em que pese essa atuação mais ativa e ampliada do Poder Judiciário gere amplas discussões na comunidade jurídica, é inquestionável que o Poder Judiciário jamais poderá se omitir diante de questões levadas a sua apreciação em face do princípio da inafastabilidade da jurisdição prevista expressamente no artigo $5^{\circ}$, inciso XXXV da Constituição Federal.

Segundo Fredie Didier Jr., Hermes Zaneti Jr. e Rafael de Oliveira (2017, p. 363) "a atuação do Poder Judiciário ocorre legitimada por uma disfunção política e não por uma atividade política e está ligada às noções que surgem a partir da ideia de 'função social' do direito e dos institutos tradicionais do direito privado".

Assim, constata-se que o alargamento da atuação do Poder Judiciário na resolução de questões atinentes a políticas públicas ou estruturas institucionais, sejam elas públicas ou privadas, não é derivada simplesmente de um voluntarismo judicial, mas de um fenômeno político-social no qual se observa a ampliação da busca pelo provimento judicial em face da inércia/omissão dos demais Poderes frente a violação de direitos fundamentais.

Nesse contexto, Edilson Vitorelli (2020, p. 115), defende que:

\begin{abstract}
A questão da judicialização de política públicas não é, portanto, um problema de ideologia do juiz, mas sim do modo com a Constituição estruturou os direitos e a atividade jurisdicional. Atribuiu-se ao Estado muito deveres materiais, e ao Poder Judiciário a obrigação de fazê-los efetivos, pela via do processo. Em outras palavras, foi a Constituição, não os juízes, que garantiu aos cidadãos diversos direitos e impôs ao Estado um grande número de deveres, sem definir, exatamente, o modo de equilibrar essa equação com as constrições orçamentárias e gerenciais da atividade administrativa.
\end{abstract}

Logo, em que pese seja viável as discussões em relação às condições e limitações com as quais o Poder Judiciário poderá intervir em políticas públicas, é quase unânime o entendimento de que algum grau de intervenção judiciária é necessário, sendo impossível distanciar o Poder Judiciário dos problemas estruturais. 
Nessa conjuntura, Fredie Didier Jr, Hermes Zaneti Jr e Rafael Oliveira (2017, p. 365) defendem que "se o Judiciário deixar de agir ele mesmo estará incorrendo na proibição de proteção insuficiente, vez que deve assegurar a efetivação dos direitos fundamentais, sendo a sua função atuar como instituição de garantia secundária" quando as garantias primárias não forem efetivas.

Seguindo esse entendimento, Estefânia Barboza e Ariadne Bonato (2015, p. 199) afirmam que "seria uma distorção e até mesmo crueldade utilizar como desculpa a separação dos poderes para negar ao Poder Judiciário a concretização das garantias e direitos fundamentais previstos na Constituição Federal”.

Outrossim, outra crítica feita a atuação do Poder Judiciário em conflitos de caráter estrutural diz respeito à suposta ausência de legitimidade democrática do magistrado haja vista que não ingressam nos seus cargos por meio da escolha democrática dos cidadãos, ou seja, não são eleitos tal como ocorre com os representantes do Poder Executivo e Legislativo.

De fato, os magistrados não exercem sua legitimidade a partir da representação popular, contudo isso não representa qualquer empecilho a sua atuação em demandas estruturais. Pelo contrário, o fato de o juiz não ser eleito pode ser interpretado inclusive de maneira benéfica diante do fato de estarem mais imunes às pressões políticas.

Nesse sentido, Ada Pellegrini Grinover (2017, p. 440) defende que a legitimidade do julgador "vem exatamente dos princípios e garantias que regem o exercício da função jurisdicional: a imparcialidade, o contraditório, a ampla defesa, a motivação das decisões, a publicidade, o controle interno e até o controle político". De igual maneira, Edilson Vitorelli (2020, p. 91) declara que "a legitimidade de uma decisão judicial decorre do modo como ela é adotada, ou seja, das constrições procedimentais para a sua construção".

A legitimidade que em tese faltaria ao magistrado é resgatada a partir da maneira pela qual o processo é guiado. Logo, é possível concluir que a legitimidade da atuação do Poder Judiciário em litígios estruturais advém da construção de um procedimento que busque a consagração dos valores previstos na Constituição Federal e a criação de um ambiente propício ao diálogo e cooperação entre as partes capaz de estimular soluções consensuais, de modo que as decisões judiciais serão legítimas por serem resultado de um procedimento pautado no diálogo.

Independemente das críticas feitas em relação à legitimidade do Poder Judiciário, fato é que o seu chamamento para resolver questões relativas a políticas públicas e problemas 
estruturais é uma realidade. Tanto o Supremo Tribunal Federal quanto o Superior Tribunal de Justiça já se posicionaram no sentido de que é possível a atuação do Poder Judiciário em praticamente todas as políticas públicas.

Agravo regimental no recurso extraordinário. Administrativo. Direito à saúde. Dever do Estado. Violação ao princípio da separação dos poderes. Não ocorrência. Precedentes. 1. O Poder Judiciário, em situações excepcionais, pode determinar que a Administração Pública adote medidas concretas, assecuratórias de direitos constitucionalmente reconhecidos como essenciais, como é o caso da saúde, dever do Estado, sem que isso configure violação do princípio da separação dos poderes. 2. Agravo regimental não provido (AI 708667 AgR, Relator: Ministro Dias Toffoli, Primeira Turma, julgado em 28.02.2012).

A intervenção do Poder Judiciário, em tema de implementação de políticas governamentais previstas e determinadas no texto constitucional, notadamente na área da educação infantil, objetiva neutralizar os efeitos lesivos e perversos, que, provocados pela omissão estatal, nada mais traduzem senão inaceitável insulto a direitos básicos que a própria Constituição da República assegura à generalidade das pessoas (ARE 639337 AgR, Relato Ministro Celso de Mello, Segunda Turma, julgado em 23.08.2011).

Se é certo que os Poderes são harmônicos entre si (art. $2^{\circ}$ da $\mathrm{CF}$ ) e que o Executivo tem prioridade indiscutível na implementação de políticas públicas indubitável também é que, em termos abstratos, o ordenamento jurídico em vigor permite que o Poder Judiciário seja chamado a intervir em situações nas quais a atitude ou a omissão do Administrados se afigure ilegítima (REsp 1.294.451-GO, Relator Ministro Herman Benjamin, julgado em 01.09.2016).

Observa-se, portanto, que parece ser tarde demais para se debruçar sobre questionamentos relacionados a possibilidade ou não da intervenção dos tribunais haja vista que isso já é feito diariamente, razão pela qual os pesquisadores devem se voltar para o estudo acerca do alcance dessa interferência, da maneira de condução desses processos, bem como da postura que deve ser adotada pelo juiz na condução desses problemas às suas soluções.

Nesse ínterim, Edilson Vitorelli traz um estudo elaborado por Daniel Brinks e Varun Gauri (2014 apud VITORELLI, 2020, p. 65), que compara dados de processos relacionados à prestação de serviços de saúde pública de cinco países: Índia, Brasil, África do Sul, Indonésia e Nigéria. Após o levantamento dos dados, os pesquisadores concluíram que o Brasil é o segundo país que obteve os piores resultados em relação aos impactos sociais de suas decisões judiciais.

Isso ocorre em face da preferência que se tem pela litigância individual em detrimento da coletiva. De fato, as ações individuais são mais ágeis e tem mais chances de obter decisões de procedência, razão pela qual costumam ser mais atraentes para os cidadãos do que as ações coletivas que em geral são mais complexas, lentas e polêmicas. Entretanto, quando se amplia o foco da situação é possível constatar que as soluções, aparentemente satisfatórias, geradas nos processos individuais que giram em torno de problemas estruturais 
acarretam a violação de qualquer critério técnico estabelecido para o fornecimento de políticas públicas.

Nessa toada, importante a lição de Edilson Vitorelli (2020, p. 63) ao afirmar que "quando problemas estruturais são tratados em processos individuais, quaisquer critérios de prioridade colapsam em um 'quem chega primeiro', de modo que quem buscar a jurisdição primeiro será atendido o que gera "apenas uma ilusão de vitória".

Ainda é relevante pontuar que não só as demandas individuais "mostram-se flagrantemente insuficientes para dar vazão às necessidades de uma discussão jurisdicional minimamente satisfatória de política públicas”, mas também as ações coletivas. Isso porque, a rigor, ao processo coletivo são aplicados os mesmos instrumentos processuais, a mesma técnica e o mesmo procedimento que são empregados nas ações individuais de modo que ele segue a mesma visão individualista e bipolarizada das ações individuais (ARENHART, 2015, p. 2).

Nota-se, assim, a inadequação da estrutura processual civil tradicional para a tratativa de litígios estruturais claramente marcados pela sua complexidade e policentrismo. O julgamento de litígios estruturais sob a ótica bipolarizada do conflito enseja dois entraves insanáveis às decisões judiciais: a sua completa ineficácia e a produção de efeitos colaterais imprevisíveis.

Ao apreciar tais litígios a partir da visão tradicional do processo, o Judiciário promove um recorte no conflito, realoca recursos indiscriminadamente, ignora problemáticas nos campos econômicos, políticos e sociais, bem como favorece aqueles que tem melhores recursos (ou ao menos que estão em condições menos desfavoráveis) para recorrer primeiro ao Judiciário.

Diante desse cenário é que Sérgio Arenhart (2015, p. 2) e Edilson Vitorelli (2020, p. 126) defendem que a atuação jurisdicional voltada para o controle de políticas pública e a efetivação de direitos fundamentais por meio de processos individuais ou coletivos não estruturais é inadequada e que, em que pese sua implementação aparente maior inofensividade, pode implicar em uma desorganização ainda maior da instituição ou administração pública.

Considerando que os problemas de natureza estrutural estão presentes nas ações individuais ou coletivas levadas ao Poder Judiciário, constata-se que a escolha se resume em aceitar o tratamento inadequado dado a esse tipo de conflito e todas as suas consequências ou 
buscar construir um processo adequado para lidar com tais litígios. Nas palavras de Edilson Vitorelli (2020, p. 115),

[...] a opção que se apresenta ao juiz não é intervir ou não em políticas públicas. É intervir bem, de forma estrutural, ou intervir mal, de modo desordenado, a partir de um conjunto de decisões individuais desconexas, que substituirão os critérios de acesso definidos pela própria política pública, pelo critério do acesso à justiça, que é o pior critério possível: ganha quem pede primeiro.

Se a judicialização de políticas públicas é inevitável, então a melhor forma de tratá-la é pela via estrutural. Diante desse contexto, surge a necessidade de aprimorar a capacidade do Poder Judiciário para a resolução de litígios estruturais de forma ordenada, racional e dialogada. Nesse ínterim, passa-se para análise acerca das diferentes abordagens que podem ser adotadas para o desenvolvimento dos processos estruturais.

\section{3 - DIFERENTES ESTRATÉgIAS DE DESENVOLVIMENTO DO PROCESSO ESTRUTURAL.}

O processo estrutural não é dotado de um procedimento próprio haja vista que seria impossível estabelecer técnicas únicas para a resolução de litígios que são altamente complexos e policêntricos, de modo que se torna necessário que o processo seja conduzido com base nas especificidades e necessidades do caso concreto.

Diante disso, constata-se que o processo estrutural pode ser construído sob distintas abordagens, mas sempre em torno de um mesmo fim: a reestruturação de uma situação de desconformidade. Nesse contexto, destacam-se os estudos realizados por Susan Sturm (1990, p. 849), professora norte-americana, responsável por catalogar quatro diferentes abordagens dos processos estruturais que podem ser adotadas para a implementação de decisões estruturais e as quais estão vinculadas a um perfil diferente de magistrado.

É importante ressaltar que o presente tópico se debruça sobre o estudo de tipos-ideais que raramente aparecem no plano da realidade em sua forma pura, mas servem de norte para a construção de uma teoria dos processos estruturais. Além disso, um juiz frequentemente irá utilizar no processo estrutural mais de uma abordagem ou então irá mudar as abordagens de acordo com cada etapa processual.

Segundo a autora (STURM, 1990, p. 849), os quatro diferentes perfis do julgador frente ao processo estrutural são: juiz deferente (deferrer), juiz diretor (director), juiz mediador (broker) e juiz catalisador (catalyst). 
A estratégia denominada "juiz diretor" coloca o magistrado ao centro do processo, sendo o grande responsável por desenvolver e implementar as medidas necessárias para a reestruturação do estado de desconformidade. A posição adotada pelo magistrado se equivale a figura de um administrador judicial pautado em uma postura ativista e gerencial e as decisões judiciais costumam ser marcadas por comandas detalhados a fim de evitar a evasão e elevar o controle exercido (STURM, 1990, p. 852-853).

Um dos exemplos trazidos pela autora (STURM, 1990, p. 854) dessa forma de conduzir o processo é o caso de Pugh v. Locke. Nesse processo, o juiz proferiu decisão estabelecendo detalhadamente as medidas que deveriam ser seguidas no dia a dia da prisão. Referida decisão foi elaborada unicamente pela corte e, portanto, não contou com a participação das partes envolvidas.

Referido modelo possui algumas vantagens, tais como: a simplificação do procedimento, a redução da sua complexidade, a garantia de maior agilidade, a facilitação do controle do cumprimento das decisões por terem ordens detalhadas e evita os problemas que são gerados quando os envolvidos não se predispõem a cooperar.

Contudo, segundo Bruno de Lima Picoli (2018, p. 87), há também muitos prejuízos desse modelo. Primeiramente, é possível pontuar que a elaboração de ordens detalhadas unicamente pela corte, em que pese facilite a fiscalização, pode acarretar a prolatação de comandos impraticáveis. Em segundo lugar, observa-se a ausência da participação das partes interessadas o que não só "reduz a aderência sócio-política à decisão estruturante", mas também tende "a minorar a legitimidade democrática do órgão pela falta de engajamento no diálogo".

Em sentido diametralmente oposto, a "estratégia deferente" enaltece o protagonismo das partes, uma vez que, nesse modelo, o juiz confia ao acusado a responsabilidade por formular o plano de reestruturação e indicar os mecanismos necessárias para a reforma da situação de desconformidade. Por sua vez, a responsabilidade pelo monitoramento do plano é deixada para o autor. $\mathrm{O}$ magistrado, portanto, adota uma postura mais passiva e age apenas quando for requisitado pelas partes (STURM, 1990, p. 849-850).

O caso Holt v. Sarver adotou esse tipo de estratégia. Trata-se de um dos casos mais paradigmáticos dos Estados Unidos, uma vez que foi a primeira vez em que se declarou judicialmente a inconstitucionalidade de todo o sistema prisional do estado do Arkansas. Nesse processo, as decisões judiciais, em geral, se limitaram a declarar situações de 
inconformidade e descreve medidas genéricas a serem tomadas, bem como estipularam prazos para a elaboração de relatórios, planos e documentos voltados para a suspensão das violações identificadas no sistema prisional de Arkansas (VIOLIN, 2020, p. 307-326).

O principal benefício da adoção da estratégia é de que a ampliação da participação das partes com a delegação da elaboração do plano de ação aos acusados faz não só com que o juiz mantenha a sua imparcialidade e sejam ampliadas as chances de que o plano elaborado seja efetivamente cumprido, mas também reduzem os custos que eventualmente seriam gastos pelo Poder Judiciário para a elaboração da solução.

Por sua vez, em que pese a participação das partes seja um dos pontos positivos da adoção do referido modelo, ela também é um dos seus obstáculos. Isso porque não há qualquer garantia de que haverá a cooperação dos interessados, uma vez que nem sempre (ou quase nunca) a instituição violadora se mostrará interessada em fazer cessar a situação violadora. Outrossim, é possível pontuar também que a estratégia deferente prejudica a participação dos titulares do direito, uma vez que o processo se centraliza na figura dos acusados.

O processo pautado na figura do "juiz mediador" é conduzido a partir do encorajamento para que as partes cheguem a uma resolução consensual do conflito. Esse modelo rejeita as sanções formais e, em seu lugar, busca exercer pressão através de seu poder de barganha informal. Observa-se a valorização do voluntarismo e consentimento como o meio apto a produzir resultados que serão aceitos pelos acusados. Essa estratégia foi aplicada pelo juiz do caso Collins v. Schoonfield que providenciou o encontro entre as duas partes a fim de tentar fazer com que ambos chegassem a um acordo, exercendo, assim, pressão nos dois lados para a resolução consensual do litígio (STURM, 1990, p. 855-856).

Por fim, a "estratégia catalizadora" se volta para o incentivo de que as partes participem de um processo deliberativo voltado a criação de uma solução eficaz. Nesse contexto, o juiz adota uma dupla abordagem ao combinar um processo deliberativo de formulação corretiva com o uso de sanções tradicionais para induzir as partes a participarem. Desse modo, as medidas necessárias à adequação institucional costumam ser discutidas entre as partes e posteriormente o julgador prolata a decisão judicial contando com o auxílio dos métodos de coerção disponíveis (STURM, 1990, p. 856-858).

A estratégia catalizadora esteve presente no processo Jackson v. Hensdrick e Spear v. Aryosha. No primeiro caso o tribunal se negou a impor uma ordem unilateral específica e, ao 
invés disso, determinou a participação de um especialista para trabalhar com as partes na formulação de uma solução sistêmica. Já no segundo caso observou-se a presença de decisões no sentido de que qualquer divergência entre as partes deveria ser submetida à mediação antes da resolução do tribunal (STURM, 1990, p. 859).

Tanto a estratégia mediadora quanto a catalizadora têm a vantagem de incentivar não só a participação das instituições violadoras, mas também dos titulares de direitos e da sociedade interessada visando, assim, a construção da solução consensual conjuntamente. Contudo, tais estratégias demandam recursos notadamente maiores quando comparadas com as demais.

Nota-se que a utilização de tais estratégias demanda "mais tempo, mais dinheiro público e privado, mais agentes envolvidos tanto para a formulação quanto para o controle das medidas, e, sobretudo, um grau de comprometimento extremado do juiz", o que nem sempre é possível diante do grande número de demandas que abundam os tribunais (PICOLI, 2018, p. 95).

A partir do que foi exposto, é possível constatar que cada uma das abordagens dos processos estruturais descritas acima possui vantagens e desvantagens, de modo que a escolha pelo tipo de estratégia a ser adotada deve ser feita de acordo com o caso concreto levando-se em consideração o problema estrutural a ser solucionado, o comportamento dos acusados e das partes interessadas, bem como a postura do julgador.

Independentemente da estratégia utilizada na condução dos processos estruturais, fato é que a condução adequada de um processo estrutural exige que o julgador tome a frente e busque a construção de um ambiente colaborativo e democrático. Nesse contexto, revela-se essencial o estudo acerca da postura que deve ser adotada pelo magistrado frente a um litígio estrutural.

\section{4 - A POSTURA ADEQUAdA dO JULGADOR PARA A RESOLUÇÃo DO LITÍGIO ESTRUTURAL}

O julgamento de litígios estruturais não é uma tarefa simples ou agradável, mas necessária. Conforme exposto anteriormente, os problemas estruturais batem à porta do Poder Judiciário diariamente e, em que pese os "juízes brasileiros estejam proferindo decisões que 
implicam reforma estrutural, ainda não existe a consciência de que os impactos concretos da ordem precisam ser avaliados de uma perspectiva sistêmica" (VITORELLI, 2017. p. 398).

Segundo Edilson Vitorelli (2020, p. 312), o julgador deve estar aberto às necessidades dos litigantes e, para tanto, é necessário "o reconhecimento de que há uma mudança na visão tradicional anglo-americana do juiz como um oráculo nas alturas, abrigado em uma toga negra de anonimato, dizendo o direito automaticamente e decidindo os fatos de modo desapaixonado".

Assim, diante de litígios estruturais não basta que o julgador se limite à vontade do legislador e aplique pura e simplesmente os comandos legislativos. Nesse sentido, observa-se que não é compatível com o processo estrutural a figura de um juiz burocrata que pode ser definido como aquele que tem forte apego às formalidades e burocracias legais de modo que a sua atuação é centrada em uma rigidez excessiva.

À medida que a tratativa de problemas estruturais pelo Poder Judiciário avançou, constatou-se a necessidade de um envolvimento maior do julgador tanto em relação às alegações trazidas pelas partes interessadas quanto no que tange ao funcionamento da instituição violadora, seja ela pública ou privada. Assim, um juiz atento às necessidades demandadas em um processo estrutural se vê obrigado a sair da sua posição de neutralidade ou passividade e a atuar de forma ativa na busca da solução que seja efetivamente eficaz.

Contudo, também não é compatível com o processo estrutural as figuras de um juiz herói ou narcisista. O juiz herói é aquele que se entende como conhecedor de todos os assuntos e se considera capaz de resolver qualquer litígio, de forma que se apropria da sua posição de poder e tomado pela ânsia de "justiça" busca fazer prevalecer a sua própria convicção. Por sua vez, o juiz narcisista é dotado de uma natureza egocêntrica, egoísta e ambiciosa que busca a admiração alheia acima de tudo e não permite o reconhecimento das necessidades do outro.

Em que pese haja a necessidade da adoção de uma postura mais ativa por parte do julgador, isso não quer dizer que ele deverá atuar em busca de exaltação pessoal e por meio da imposição unilateral da sua vontade tolhendo qualquer espaço para o diálogo. Na realidade, durante a condução de litígios estruturais é preferível que o juiz atue mais como um agente de troca e cooperação a fim de tornar o processo um palco de negociações e debates.

O julgador deve estar atento aos dispositivos do Código de Processo Civil de 2015 que conduzem à cooperação, negociação processual, flexibilidade, diálogo e a efetividade da 
decisão judicial. Nesse teor, é fundamental que o juiz se liberte das amarras das técnicas processuais tradicionais, uma vez que diante de processos estruturais não basta que o magistrado se limite a decidir entre o deferimento, o deferimento parcial ou o indeferimento da postulação (DIDIER, ZANETI, OLIVEIRA, 2017, p. 362).

Além disso, o magistrado deve ser capaz de emitir comandos condizentes com o caso concreto e que sejam capazes de atingir o melhor resultado. Segundo Desirê Bauermann (2017, p. 287), os juízes norte-americanos se guiam pelo princípio da equity, caracterizado "pela flexibilidade oferecida ao Judiciário para que formate as medidas a serem utilizadas para o atendimento do direito de acordo com o caso concreto, e também pela facilidade com que conciliam e ajustam necessidades públicas e privadas”.

Logo, a todo momento o juiz deve se ater às consequências das suas decisões, analisar o custo de cada medida a ser adotada e os benefícios gerados, bem como verificar se outros membros da sociedade não restarão prejudicados. Para tanto, é necessário que o julgador se mantenha aberto ao diálogo com a população e com outros ramos do governo. É indicado também que, sempre que for necessário, o Judiciário busque o auxílio de especialistas a fim de ter a melhor dimensão possível acerca do conflito.

Jordão Violin (2017, p. 337) questiona o protagonismo do magistrado em um processo estrutural e aponta para o papel dos advogados como o "elemento decisivo para o sucesso ou insucesso da reforma estrutural", uma vez que "a eles cabe definir os limites objetivos e subjetivos da causa, identificar as prioridades, definir as estratégias e elaborar os argumentos que sustentarão a sentença". Nesse aspecto, insere-se também a figura dos representantes do Ministério Público, uma vez que, no Brasil, é comum que os processos estruturais se iniciem a partir da atuação do referido órgão.

A fim de elucidar melhor essa questão é possível trazer o exemplo de uma demanda ligada à desigualdade salarial entre homens e mulheres. Se ela tiver como finalidade garantir a igualdade salarial de um indivíduo, ela será um litígio individual. Se o problema for garantir o respeito a igualdade salarial em uma determinada empresa, será um litígio coletivo local. Contudo, se for apreciado a partir de uma perspectiva ligada à necessidade de implementação de políticas públicas ou a reestruturação da instituição, será um litígio estrutural.

De fato, a petição inicial e a natureza da causa de pedir é capaz de direcionar o magistrado à análise do problema a partir das suas características estruturais ao invés de simplesmente conduzir o processo da forma tradicional o que, conforme já analisado, não é 
adequado para a resolução de litígios estruturais. Entretanto, segundo Edilson Vitorelli (2020, p. 302) "o pedido estrutural não é garantia de uma condução estrutural do processo. Esta depende, fundamentalmente, do juiz". Assim, "se o magistrado não considerar conveniente conduzir o processo estruturalmente, não há como forçá-lo".

Contudo, em que pese a importância do magistrado na condução do processo estrutural, nota-se que o sucesso do processo não está vinculado apenas a atuação do julgador. É essencial, além da colaboração dos advogados e representantes do Ministério Público, a cooperação das partes envolvidas, uma vez que, a depender do caso concreto, a solução adequada dos litígios estará sujeita à atuação ativa dos obrigados no desenvolvimento e implementação de planos de ação. Segundo Jordão Violin (2017, p. 433), "sem a cooperação, o juiz pode se ver às voltas com atrasos e descumprimento deliberado - o que erode pouco a pouco sua credibilidade".

É perfeitamente admissível um processo estrutural majoritariamente impositivo, contudo a sua condução imperativa demandará altos custos do Poder Judiciário que terá que tomar a frente de toda a reestruturação da situação e se valer de sanções que nem sempre garantirão o cumprimento da ordem. Assim, a condução dialogada e cooperativa sempre será a mais indicada para o alcance de boas soluções, haja vista que apenas dessa forma será possível tomar conhecimentos acerca das necessidades dos titulares de direitos e das possibilidades das instituições e dos demais ramos do poder.

Verifica-se, portanto, que a condução adequada de um processo estrutural está condicionada ao envolvimento e comprometimento de todas as partes. $\mathrm{O}$ advogado tem o papel de definir os objetivos, apontar as prioridades, colacionar os interesses das partes e elaborar argumentos capazes de convencer o juiz. Por sua vez, o juiz tem a função de construir um ambiente propício ao diálogo e a negociação, bem como de atuar ativamente sempre que se mostrar necessário. Por fim, as partes, em especial os obrigados, tem a função de cooperar com o juízo, bem como de participar da elaboração dos planos de ação e efetivamente cumprir o que fora acordado.

\section{CONSIDERAÇÕES FINAIS}

A partir do desenvolvimento da presente pesquisa, constatou-se que, em que pese existam inúmeras discussões em relação a atuação mais ativa e ampliada do Poder Judiciário, é inquestionável que o seu envolvimento na solução de litígios que se relacionam com a 
estrutura da sociedade é uma realidade e que o Judiciário jamais poderá se omitir diante das questões levadas a sua apreciação.

A rigor, verificou-se também que a atuação em litígios estruturais não foi uma escolha do Poder Judiciário, mas sim um problema político-social que levou a ampliação da busca pelo provimento judicial em face da inércia/omissão dos demais Poderes frente a violação de direitos fundamentais. Diante desse contexto, é que se reconheceu a necessidade de que os pesquisadores se voltem para o estudo acerca da maneira de condução desses processos e da postura que deve ser adotada pelo juiz na condução desses problemas às suas soluções.

Nesse sentido, constatou-se que não são compatíveis com o processo estrutural as figuras de um juiz burocrata, herói ou narcisista e que as especificidades dos conflitos de caráter estrutural exigem que o juiz atue como um agente de troca e cooperação a fim de construir um ambiente colaborativo e democrático a fim de obter as melhores soluções para o conflito.

Por fim, verificou-se que a condução estrutural do processo depende fundamentalmente do juiz, mas que o sucesso do processo a partir do alcance de solução eficaz e da cessação da violação de direitos fundamentais não será alcançado apenas por meio da atuação do julgador, sendo essencial a cooperação de todas as partes envolvidas, incluindo os advogados, os titulares de direitos e os obrigados.

\section{BIBLIOGRAFIA}

ARENHART, Sérgio. Processos Estruturais no direito brasileiro: reflexões a partir do caso da ACP do carvão. In Revista de Processo Comparado, vol. 2, dez./2015. Disponível em: http://revistadeprocessocomparado.com.br/wp-content/uploads/2016/01/ARENHART-SergioArtigo-Decisoes-estruturais.pdf. Acesso em: 06 set. 2021.

BARROSO, Luís Roberto. Judicialização, ativismo judicial e legitimidade democrática. Vol. 5, $\mathrm{n}^{\circ}$ 1. Universidade do Estudo do Rio de Janeiro, 2012.

BAUERMANN, Desirê. Structural injuctions no direito norte-americano. In ARENHART, Sérgio Cruz; JOBIM, Marco Felix (org.). Processos estruturais. Salvador: Juspodivm, 2017. 
BONATI, Ariadne Nascimento da Silveira. BARBOZA, Estefânia Maria de Queiroz. A Judicialização e o ativismo judicial no âmbito das políticas públicas. In SOUZA, André Peixoto de (org.). Estado, Poder e Jurisdição. Rio de Janeiro: LMJ Mundo Jurídico, 2015.

CHIOVENDA, Giuseppe. Instituições de direito processual civil. v. 1. São Paulo: Saraiva, 1969. p. 5.

DIDIER JR., Fredie; ZANETI JR., Hermes; OLIVEIRA, Rafael Alexandria de. Notas sobre as decisões estruturantes. In ARENHART, Sérgio Cruz; JOBIM, Marco Felix (org.).

Processos estruturais. Salvador: Juspodivm, 2017.

FISS, Owen. Um Novo Processo Civil: Estudos norte-americanos sobre jurisdição, constituição e sociedade. São Paulo: Editora Revista dos Tribunais, 2004.

FLETCHER, William A. The discretionary constitution: institutional remedies and judicial legitimacy. In The Yale Law Journal, v. 91, n. 4, p. 635-697, mar. 1982. Disponível em: https://core.ac.uk/download/pdf/160249072.pdf. Acesso em: 06 set. 2021.

FULLER, Lon L. The Forms and Limits of Adjudication. In Harvard Law Review, v. 92, n. 2, p. 353-409, dez. 1978. Disponível em: https://www.jstor.org/stable/1340368. Acesso em: 06 set. 2021.

GRINOVER, Ada Pellegrini. Caminhos e descaminhos do controle jurisdicional de políticas públicas no Brasil. In WATANABE, Kazuo (et al) (ortg.). O Processo Para Solução de Conflitos de Interesse Público. Salvador: JusPODIVM, 2017, p. 440.

JOBIM, Marco Felix. Medidas estruturantes: da Suprema Corte Estaduniense ao Supremo Tribunal Federal. Porto Alegre: Livraria do Advogado Editora, 2013.

STURM, Susan. Resolving the remedial dilemma: Strategies of judicial interventions in prisons. In University of Pennsylvania Law Review, vol. 138, 1990. 
VIOLIN, Jordão. Holt v. Sarver e a reforma do sistema prisional no Arkansas. In ARENHART, Sérgio Cruz; JOBIM, Marco Felix (org.). Processos estruturais. Salvador: Juspodivm, 2017.

VITORELLI, Edilson. Processo Civil Estrutural: Teoria e Prática. Salvador: Editora Juspodivm, 2020.

VITORELLI, Edilson. Levando os conceitos a sério: processo estrutural, processo coletivo, processo estratégico e suas diferenças. Revista de Processo, vol. 284, out./2018.

VITORELLI, Edilson. Litígios Estruturais: decisão e implementação de mudanças socialmente relevantes pela via processual. In ARENHART, Sérgio Cruz; JOBIM, Marco Felix (org.). Processos estruturais. Salvador: Juspodivm, 2017. 